\title{
Kajian Materi Shalat pada Kitab Mabadi'ul Fiqhiyyah Juz II dan Fiqh Kementerian Agama RI di MI Nahdlatussalam Anjir Serapat Kabupaten Kuala Kapuas
}

\author{
Muhammad Fadilah', Rofi'i ${ }^{2}$ \\ ${ }^{1}$ IAIN Palangka Raya, Kota Palangka Raya, Indonesia \\ E-mail : fadilah.al.husain07@gmail.com \\ ${ }^{2}$ IAIN Palangka Raya, Kota Palangka Raya, Indonesia
}

\begin{abstract}
ABSTRAK
Materi fiqh tentang shalat yang merupakan sangat berperan penting dan menjadi asas utama bagi para peserta didik dalam melaksanakan ibadah keseharian, terutama ibadah shalat. di antaranya adalah menggunakan kitab Mabadi'ul Fiqhiyyah Juz II. Kitab Mabadi'ul Fiqhiyyah Juz II tersebut merupakan salah satu indikator yang sangat berperan penting bagi pengetahuan peserta didik yang baru belajar dalam memahami fiqh. Kitab tersebut juga merupakan salah satu ciri khas dari MI Nahdlatussalam yang beroreintasi pendidikan salafi dan berkolaburasi dengan pendidikan umum yang juga mengajarkan buku fiqh Kementerian Agama RI. Tujuan penelitian ini adalah (1) untuk mendeskripsikan materi shalat di kitab Mabadi'ul Fiqhiyyah Juz II dengan materi fiqh kurikulum Kementerian Agama RI. Penelitian ini menggunakan metode kualitatif deskriptif yang digali melalui data-data wawancara dan dokumentasi. Hasil penelitian menunjukkan bahwa: (1) Materi shalat pada kitab Mabadi'ul Fiqhiyyah Juz II membahas tentang: syarat wajib shalat, syarat sah shalat, shalat fardhu dan waktunya, shalat sunnah yang mengikuti shalat fardhu, waktu-waktu yang diharamkan shalat, rukun shalat, sunnah-sunnah di dalam shalat, dan hal-hal yang membatalkan shalat. Sedangkan materi fiqh kurikulum Kementerian Agama RI membahas tentang: syarat wajib shalat, syarat sah shalat, rukun shalat, sunnah-sunnah di dalam shalat, dan hal-hal yang membatalkan shalat.

Kata kunci: fiqh, Mabadi'ul Fiqhiyyah Juz II, dan shalat
\end{abstract}

\begin{abstract}
Fiqh material about prayer which is very important and becomes the main principle for students in carrying out daily worship, especially prayer. among them is using the book Mabadi'ul Fiqhiyyah Juz II. Book Mabadi'ul Fiqhiyyah Juz II is one indicator that is very important for the knowledge of students who are just learning in understanding fiqh. The book is also one of the characteristics of MI Nahdlatussalam which has salafi education and collaboration with general education which also teaches fiqh books of the Indonesian Ministry of Religion. The purpose of this study is (1) to describe the material of prayer in the book of Mabadi'ul Fiqhiyyah Juz II with fiqh material of the Ministry of Religion's curriculum. This study uses descriptive qualitative methods that were extracted through interview data and documentation. The results showed that: (1) The material for prayer in the Mabadi'ul Fiqhiyyah Juz II discusses about: the obligatory conditions of prayer, the legal requirements for prayer, prayer of fardhu and its time, sunnah prayer which follows the prayer of fardhu, the times that are forbidden to pray, the pillars of prayer,
\end{abstract}


sunnah-sunnah in prayer, and things that cancel prayer. While the subject matter of the fiqh curriculum of the Ministry of Religion of the Republic of Indonesia discusses: the obligatory conditions of prayer, the legal requirements for prayer, the pillars of prayer, the sunnahs in prayer, and the things that cancel prayer.

Keywords: fiqh, Mabadi'ul Fiqhiyyah Juz II, and prayer

\section{Article history:}

Received : 16-2-2019

Revised : 10-2-2020

Accepted : 12-2-2020

\section{PEndahuluan}

Belakangan ini pendidikan lebih mengutamakan pembelajaran umum daripada pembelajaran agama. Mengapa demikian, karena pendidikan umum muncul sebagai reaksi terhadap kecenderungan masyarakat modern terhadap produk teknologi dan cenderung mengabaikan ilmu keagamaan, seperti ilmu fiqh. Fiqh merupakan sebuah koleksi daya upaya para fuqaha dalam menerapkan syariat Islam sesuai dengan kebutuhan masyarakat. Fiqh diidentikkan dengan hukum atau ketentuanketentuan yang menjadi peraturan hidup manusia yang bersifat mengendalikan, mencegah, mengikat, dan memaksa.

Fiqh hendaknya dikenalkan dari sejak anak-anak dengan tujuan untuk menumbuhkan pengetahuan mereka terhadap ilmu fiqh. Di MI Nahdlatussalam merupakan salah satu sekolah yang mengajarkan tentang fiqh, bahkan di sekolah tersebut menggunakan dua figh, yaitu fiqh dari kurikulum Kementrian Agama RI dan kitab Mabadi'ul Fiqhiyyah Juz II. Di antara materi fiqh kurikulum Kementrian Agama RI yang ada di MI Nahdlatussalam meliputi : shalat fardhu. Sedangkan kitab fiqh yang digunakan adalah kitab Mabadi'ul Fiqhiyyah Juz II sebagai penunjang wawasan dan pengetahuan peserta didik terhadap ilmu fiqh di antaranya materi tentang shalat fardhu, meliputi: syarat wajib shalat, syarat sah shalat, shalat fardhu dan waktunya, shalat sunnah yang mengikuti shalat fardhu, waktu yang diharamkan shalat, 
rukun shalat, sunnah-sunnah di dalam shalat, dan hal-hal yang membatalkan shalat.

Kitab Mabadi'ul Fiqhiyyah merupakan kitab bermadzhab Imam Asy-Syafi'i yang disusun oleh Umar Abdul Jabbar yang membahas tentang ibadah keseharian, seperti: thaharah, najis, istinja', mandi wajib, tayamum, shalat, zakat, puasa, haji, dll. Hal demikian sering dikenal dengan sebutan Fiqh. Fiqh adalah suatu bidang ilmu dalam syariat Islam yang secara khusus membahas persoalan hukum yang mengatur kehidupan manusia. Kitab ini menyajikan materi yang mudah dipahami bagi para pemula yang ingin mempelajari tentang fiqh. Kitab tersebut dikemas sedemikian rupa dan secara ringkas dalam sebuah kitab berbahasa Arab yang menggunakan metode tanya jawab. Kitab Mabadi'ul Fiqhiyyah Juz II merupakan salah satu indikator yang sangat berperan penting bagi pengetahuan peserta didik yang baru belajar dalam memahami fiqh. Kitab tersebut juga merupakan salah satu ciri khas dari MI Nahdlatussalam yang beroreintasi pendidikan salafi dan berkolaburasi dengan pendidikan umum yang juga mengajarkan buku fiqh Kementerian Agama RI. Kitab tersebut digunakan karena merupakan salah satu kebutuhan masyarakat khususnya pada anak-anak yang minim akan pengetahuan dibidang fiqh terutama tentang shalat. Dengan demikian, keberadaan kedua buku fiqh yaitu kitab Mabadi'ul Fiqhiyyah Juz II dan buku fiqh kurikulum Kementerian Agama RI yang diajarkan di MI Nahdlatussalam tentunya sesuatu hal yang unik untuk dikaji.

\section{METODE}

Dengan melihat pokok permasalahan, maka penelitian menggunakan metode jenis penelitian lapangan dan library research dengan pendekatan Analysis Deskriptif. Adapun alasan menggunakan metode di atas, karena judul yang diangkat bersifat analisis deskriptif dan materi fiqh 
tentang shalat pada kitab Mabadi'ul Fiqhiyyah Juz II mempunyai peranan yang sangat penting bagi wawasan dan pengetahuan peserta didik sehingga perlu dideskripsikan, maka secara metodologis materi yang telah ditetapkan oleh penulis sebagai objek penelitian dan dilakukan dengan metode kualitatif jenis penelitian lapangan dan library research dengan mengumpulkan datadata yang terkait dengan judul yang penulis teliti.

Sumber data yang digali dalam penelitian ini bersumber dari: Sumber primer, yaitu data yang langsung dikumpulkan oleh peneliti (atau petugasnya) dari sumber pertamanya (Sumadi Suryabrata, 2011: 93). Sumber primer ialah data yang bersumber dari sumber asli atau pertama (Sarwono Jonathan, 2006: 129). Adapun yang menjadi sumber primer dalam penelitian ini adalah kitab Mabadi'ul Fiqhiyyah Juz II dan buku fiqh kurikulum Kementerian Agama RI di MI Nahdlatussalam. Sumber skunder, yaitu data yang langsung dikumpulkan oleh peneliti sebagai penunjang dari sumber pertama. (Sumadi Suryabrata, 2011: 93), atau sumber skunder adalah datadata yang didapat dari berbagai macam sumber lainnya yang dapat menunjang data utama, seperti surat-surat pribadi, buku harian, dokumendokumen resmi dari instansi pemerintah atau juga berupa majalah. Adapun yang menjadi sumber skunder dalam penelitian ini adalah sumbersumber yang berkaitan dengan penelitian ini, seperti kitab Ilmu Fiqih Muhammad Sarni, Fathul Qarib Sulaiman Rasyid. Sumber tersier ialah pendukung dari bahan skunder dari buku kamus bahasa Indonesia, kamus bahasa Inggris, kamus bahasa Arab, kamus ilmiah populer, internet, dan bukubuku tentang fiqih.

\section{HASIL DAN PEMBAHASAN}

\section{A. Materi shalat Kitab} Mabadi'ul Fiqhiyyah Juz II Fiqh adalah suatu pemahaman terhadap sesuatu hukum atau 


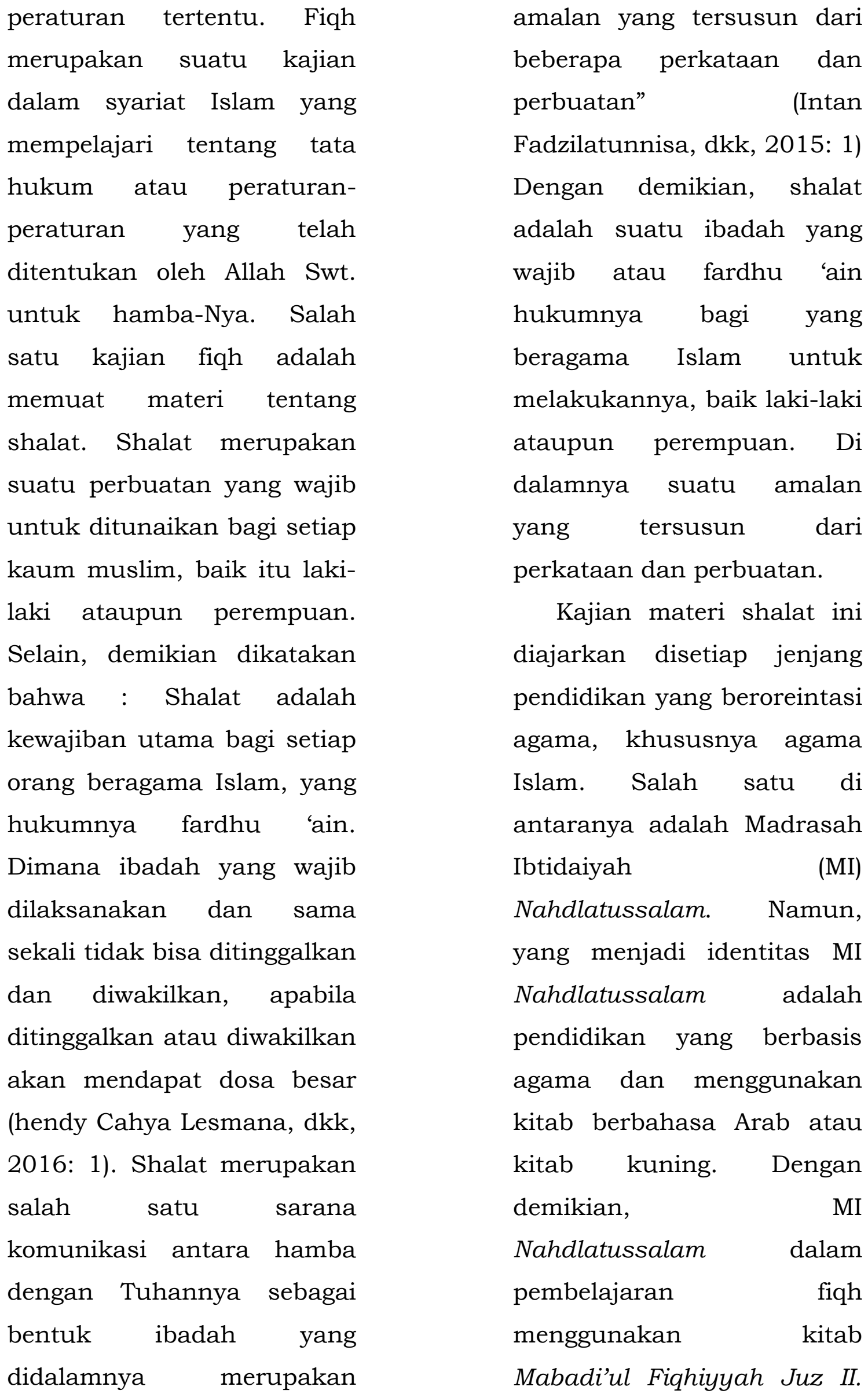


Kitab Mabadi'ul Fiqhiyyah Juz II merupakan kitab berfaham Asy-Syafi'i yang dikemas sedemikian rupa agar mudah dipahami bagi para pemula yang mengenal dan mempelajari ilmu fiqh.

Terkait dengan penelitian yang dilakukan oleh peneliti terhadap kitab Mabadi'ul Fiqhiyyah Juz II adalah materi tentang shalat. Adapun materi tersebut adalah sebagai berikut: 1) Syarat wajib Shalat : beragama Islam, dewasa dan berakal sehat. Syarat wajib shalat merupakan syarat utama yang mewajibkan seseorang dalam melaksanakan shalat. 2) Syarat sah shalat : Suci badan, pakaian, dan tempat dari semua najis, menutup aurat, mengetahui masuknya waktu shalat, menghadap kiblat. Syarat sah shalat ada empat macam, yang mana syarat tersebut menjadi syarat mutlak bagi seorang muslim dalam melakukan shalat.
Apabila salah satu syarat tersebut tidak dipenuhi, maka shalatnya dianggap tidak sah atau batal. Hal ini senada dengan pendapat Habbiyallah dalam buku Figh dan Ushul Fiqh bahwa syarat sah shalat ada empat macam, yaitu: pertama, suci tubuh, pakaian dan tempat shalat. kedua, masuknya waktu shalat. Ketiga, menghadap kiblat. Keempat, menutup aurat (Hasbiyallah, 2013: 178-179). Melihat dari pernyataan tersebut dapat disimpulkan bahwa syarat sahnya melakukan shalat bagi setiap muslim ada empat, jika salah satu di antaranya tidak dilakukan, maka shalat seseorang dianggap tidak sah. Namun, dalam penjelasan materi syarat sah shalat di dalam kitab Mabadi'ul Fiqhiyyah Juz II ini hanya menjelaskan secara global atau menyeluruh, tidak dijelaskan secara rinci dari setiap point hal-hal yang menjadi syarat sahnya shalat bagi setiap muslim. Di samping tidak 
ada penjelasan terkait dengan dalil penguat terhadap syarat sahnya melakukan shalat bagi setiap kaum muslim. 1) Shalat fardhu dan waktunya. Shalat fardhu adalah shalat yang diwajibkan oleh Allah Swt. kepada setiap muslim yang baliq lagi berakal. Shalat fardhu merupakan suatu kewajiban yang langsung diberikan Allah Swt. kepada Nabi Muhammad melalui Isra' dan Mi'raj. Pada malam itu nabi Muhammad SAW. Menerima sebuah amanah langsung dari Allah Swt. berupa perintah shalat untuk dia dan ummatnya. Sebagaimana firman Allah SWT. dalam Al-Qur'an sebagai berikut:

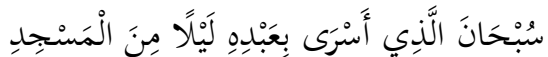

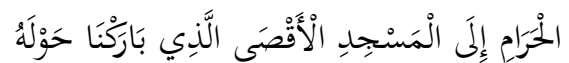



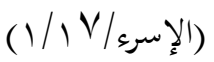

Artinya:

"Maha suci (Allah), yang telah memperjalankan hamba-Nya (Muhammad) pada malam dari Masjidil Haram ke Masjidil Aqsha yang telah kami berkahi sekelilingnya agar kami memeperlihatkan kepadanya sebagian tanda-tanda (kebesaran) kami. Sesungguhnya Dia adalah maha mendengar, maha mengetahui." (Kemenang RI, 2012: 384) Shalat yang diperintahkan melalui Isra' dan Mi'raj adalah shalat fardhu lima kali dalam sehari semalam, yaitu shalat yang mewajibkan bagi setiap kaum muslim untuk melaksanakannya. Adapun untuk memperjelas pelaksanaan shalat dan waktunya dapat dilihat dari hadits nabi Muhammad Saw. sebagai berikut:

عَنْ عَبْدِ اللهِ بْنِ عَمْرِو أَنَّ رَسُوْلَ اللهِ صَلَّلى اللهُ



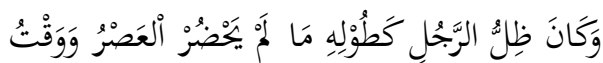



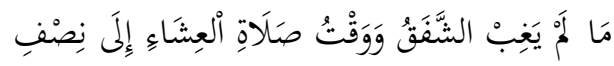

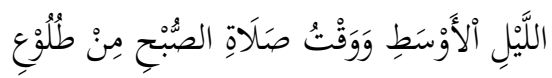

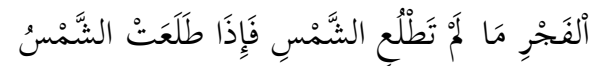



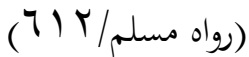


Artinya:

tergelincir

sampain

"Rasulullah Saw. telah

bayang-bayang seseorang

bersabda, waktu dzuhur adalah jika matahari telah tergelincir sampain bayangbayang seseorang itu sama dengan bayang-bayangnya, yaitu sebelum datang waktu ashar. Waktu ashar adalah sampai matahari belum kuning cahayanya. Waktu maghrib selama syafaq atau awan yang merah belum lenyap. Waktu shalat isya sampai tengah malam kedua, sedangkan shalat shubuh mulai terbit fajar samapi terbit matahari. Jika matahari telah terbit, maka hentikanlah shalat karena saat itu ia terbit di antara kedua tanduk setan." (Imam An-Nawawi, 2010: 317-318).

Dari hadits tersebut maka dapat dipahami bahwa, shalat fardhu ada lima, yaitu: shalat dzuhur, ashar, maghrib. isya, dan shubuh. Sedangkan waktunya adalah sebagai berikut:

a. Shalat dzuhur waktunya adala jika matahari telah

itu sama dengan bayangbayangnya.

b. Shalat ashar waktunya adalah sampai matahari belum kuning cahayanya.

c. Shalat maghrib waktunya adalah selama syafaq atau awan yang merah belum lenyap.

d. Shalat isya waktunya adalah sampai tengah malam kedua.

e. Shalat shubuh waktunya adalah mulai terbit fajar sampai terbit matahari.

Dalam penjelasan kitab Mabadi'ul Fiqhiyyah Juz II terkait dengan materi shalat fardhu dan waktunya hanya menyebutkan jumlah shalat fardhu dan waktunya saja, tetapi tidak disertai dengan dalil ataupun hadits-hadits yang terkait dengan materi tersebut, seperti sabda Rasululah SAW. yang diriwayatkan oleh Imam Muslim di atas. 3) Shalat sunnah yang mengikuti shalat fardhu. Shalat 


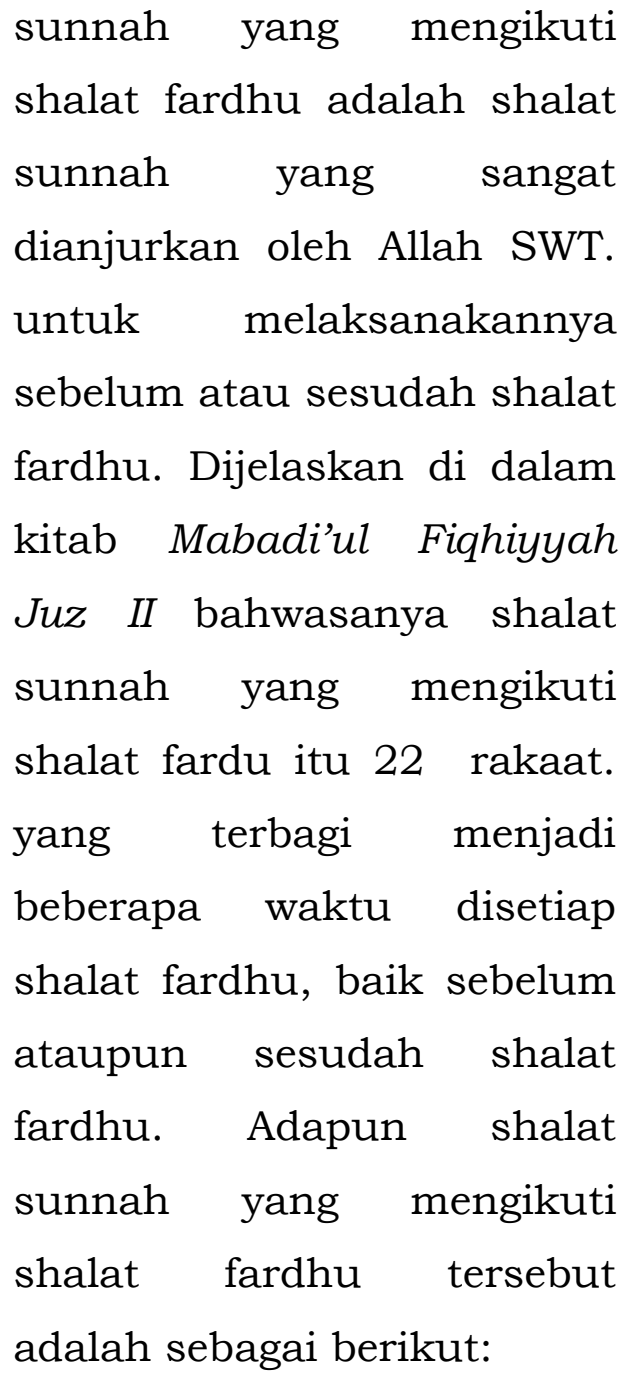

a. Shalat sunnah dua rakaat sebelum shalat shubuh

b. Shalat sunnah empat rakaat sebelum shalat dzuhur dan empat rakaat sesudahnya

c. Shalat sunnah empat rakaat sebelum shalat ashar

d. Shalat sunnah dua rakaat sebelum shalat maghrib dan dua rakaat sesudahnya e. Shalat sunnah dua rakaat sebelum shalat isya dan dua rakaat sesudahnya

Menurut Nursyamsudin bahwa, shalat shalat sunnah yang demikian disebut dengan shalat sunnah rawatib. Shalat sunnah rawatib adalah shalat sunnah yang dikerjakan sebelum atau sesudah shalat fardhu. Shalat sunnah yang dikerjakan sebelum shalat fardhu disebut shalat sunnah qabliyah, sedangkan shalat sunnah yang dikerjakan sesudah shalat fardhu disebut shalat sunnah ba'diyah (Nursyamsudin, 2012: 89). Dari pendapat di atas dapat dipahami bahwa shalat sunnah yang mengikuti shalat fardhu itu ada 22 rakaat, yaitu: pertama, empat rakaat sebelum shalat dzuhur dan empat rakaat sesudahnya. Kedua, empat rakaat sebelum shalat ashar. Ketiga dua rakaat sebelum shalat maghrib dan dua rakaat sesudahnya. 
Keempat, dua rakaat sebelum shalat isya dan dua rakaat sesudahnya. Kelima, dua rakaat sebelum shalat shubuh. Namun, pada kitab waktu tertentu. Allah Swt. berfirman dalam Al-Qur'an:

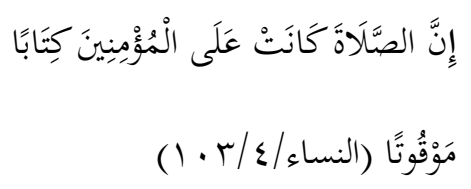

Mabadiul Fiqhiyyah Juz II terkait dengan materi Shalat sunnah yang mengikuti shalat fardhu penjelasannya hanya secara global. Tidak disertai dengan dalil atau hadits yang terkait dengan materi tersebut. Misalnya Rasulullah Saw. bersabda:



Artinya:

"Dari Ummi Habibah, ia berkata, Rasulullah Saw. bersabda: barangsiapa mengerjakan shalat sunnah empat rakaat sebelum dzuhur dan empat rakaat setelah dzuhur, maka Allah mengharamkan api Neraka untuk menyentuhnya." (Muhammad Nashiruddin AlAlbani, 2007: 358).

Dalam pelaksanaan shalat tentunya mempunyai

Artinya:

"Sungguh, shalat itu adalah kewajiban yang ditentukan waktunya atas orang-orang yang beriman." (Kemenang RI, 2012: 125).

Namun, ada beberapa shalat yang boleh dilakukan kapan saja, di antaranya shalat sunnah taubah, shalat sunnah wudhu, dll. Selain hal demikian, tentu juga ada waktu-waktu yang diharamkan dalam pelaksanaan sholat. Dalam kitab Mabadi'ul Fiqhiyyah Juz II, bahwa waktu-waktu yang diharamkan shalat ada 5 macam, yaitu: pertama, Sesudah terbitnya matahari hingga naik sekira setinggi tombak. Kedua, ketika Istiwa' (tengah hari), kecuali hari Jum'at. Ketiga, ketika menguningnya matahari hingga ia terbenam. Keempat, sesudah shalat 
$\begin{array}{lrr}\text { shubuh hingga } & \text { terbit } \\ \text { matahari. Kelima, } & \text { sesudah } \\ \text { shalat ashar } & \text { hingga } \\ \text { terbenamnya } & \text { matahari. } \\ \text { Pernyataan di atas } & \text { senada } \\ \text { dengan } & \text { pendapat }\end{array}$ Muhammad Nashiruddin AlAlbani dalam buku Shahih Sunan Nasa'i, bahwa waktuwaktu yang diharamkan shalat dijelaskan beberapa hadits nabi Muhammad SAW. sebagai berikut: Larangan shalat setelah shalat shubuh

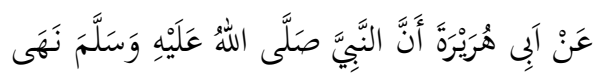

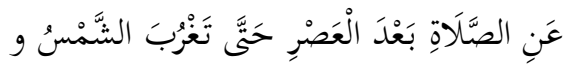

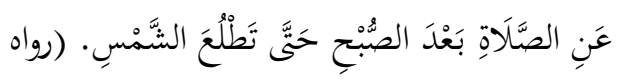

$$
\begin{aligned}
& \text { النسائى/ • } 07
\end{aligned}
$$

Artinya:

"Dari Abu Hurairah, bahwa nabi Muhammad Saw. melarang shalat setelah ashar hingga matahari terbenam dan melarang shalat setelah shubuh hingga matahari terbit." (Muhammad Nashiruddin AlAlbani, 2004: 254).

Larangan shalat setelah shalat ashar

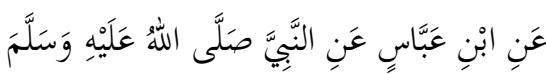



$$
\begin{aligned}
& \text { (رواه النسائي/071) }
\end{aligned}
$$

Artinya:

"Dari Ibnu Abbas, bahwa nabi SAW. melarang shalat setelah shalat ashar" (Muhammad Nashiruddin AlAlbani, 2004: 256).

Larangan shalat pada waktu matahari baru terbit hingga meninggi, matahari menjelang terbenam hingga terbenam dan waktu tengah hari

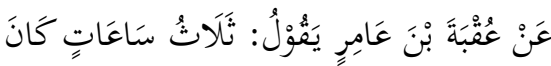

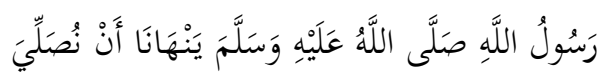



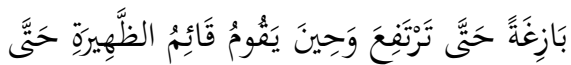

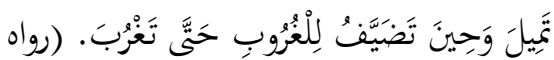

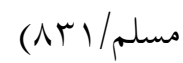

Artinya:

"Dari Uqbah bin Amir AlJuhani berkata: ada tiga waktu dimana Rasulullah Saw. melarang kita untuk menunaikan shalat ketika itu atau (melarang kita) untuk memakamkan orang 
yang meninggal di antara kita, yaitu ketika matahari terbit sampai benar-benar terangkat ke atas ufuk, ketika matahari tepat di atas ubun-ubun, dan ketika matahari akan terbenam sampai benar-benar tenggelam (Imam AnNawawi, 2010: 318)

Melihat beberapa penjelasan hadits di atas bahwa, nabi Muhammad telah melarang umatnya untuk shalat setelah shalat shubuh hingga terbit matahari, setelah shalat ashar, waktu tengah hari kecuali hari jum'at, ketika matahari terbenam, dan ketika matahari terbit sampai tinggi bagai ujung tombak.

Rukun shalat adalah suatu perkataan atau perbuatan yang akan membentuk hakikat shalat, maksudnya adalah intisari dari shalat. Rukun shalat merupakan sesuatu yang harus dipenuhi dalam shalat, jika salah satunya saja tertinggal atau lupa, baik disengaja maupun tidak disengaja, maka shalatnya dianggap tidak sah atau batal.

Dijelaskan di dalam kitab Mabadiul Fiqhiyyah Juz II, bahwa rukun shalat ada 14 , yaitu:

a. Berdiri bagi yang kuasa di dalam shalat fardhu

b. Niat

c. Takbiratul ihram

d. Membaca Al-Fatihah

e. Ruku'

f. Thuma'ninah dalam ruku', i'tidal, sujud dan duduk

g. I'tidal

h. Sujud

i. Duduk antara dua sujud

j. Duduk untuk membaca tasyahud akhir

k. Tasyahud akhir

1. Membaca shalawat atas nabi Muhammad Saw. dalam tasyahud akhir m. Mengucap salam yang pertama

n. Tertib

Dengan demikian, bahwa rukun shalat dalam kitab Mabadi'ul Fiqhiyyah Juz II ada 14 macam. Namun, 
pada penjelasannya bersifat inti, tidak disertai dengan dalil atau hadits-hadits yang terkait setiap point yang ada pada materi rukun shalat. Misalkan sabda nabi Muhammad Saw. tentang membaca surah Al-Fatihah

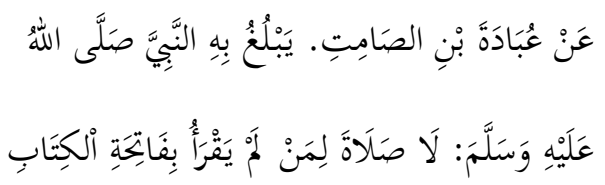



Artinya:

"Dari Ubadah bin AshShamit, ia menyampaikan kalau nabi Saw. bersabda: tidak sah shalat seseorang yang tidak membaca pembuka Al-Qur'an (Surah Al-Fatihah)." (Imam AnNawawi, 2010: 340)

B. Materi

\section{Kurikulum}

shalat

Fiqh

\section{Agama RI}

MI

Nahdlatussalam

merupakan sekolah berbasis agama dan juga tidak lepas dari kurikulum dari pemerintah. Di antara salah satu mata pelajaran yang diajarkan di MI Nahdlatussalam adalah mata pelajaran fiqh kurikulum
Kementerian Agama RI. Terkait dengan materi tentang shalat, khususnya shalat fardhu terletak pada kelas II MI Nahdlatussalam.

Materi syarat sah shalat pada fiqh kurikulum Kementerian Agama RI ini menjelaskan beberapa point penting terkait dengan materi tersebut. Namun ada juga beberapa point materi tersebut tidak dijelaskan, seperti suci dari kecil dan besar. Selain demikian, materi ini juga disertai dengan kuis berupa mencocokkan tabel yang telah disediakan pada buku tersebut.

Rukun shalat merupakan sesuatu yang harus dipenuhi untuk sahnya suatu perbuatan, seperti di dalam shalat. Disebutkan di dalam buku fiqh kurikulum MI Nahdlatussalam bahwa rukun shalat ada 13 yaitu:

Materi rukun shalat pada buku fiqh kurikulum Kementerian Agama RI ini berjumlah 13 rukun. Namun dalam setiap rukun tersebut hanya menjelaskan secara 
global sehingga peserta didik kurang memahami terhadap materi tersebut. selain demikian materinya tidak disertai hadits sebagai dasar.

Sunnah merupakan segala sesuatu yang dianjurkan untuk melakukannya, apabila melakukan mendapat pahala dan jika meninggalkannya tidak mendapat dosa. Adapun sunnah-sunnah shalat dalam buku fiqh kurikulum Kementerian Agama RI bahwa sunnah-sunnah shalat ada 8 , yaitu:

a. Ketika takbiratul ihram mengangkat kedua tangan

b. Mengangkat kedua tangan ketika ruku', berdiri dari ruku', dan berdiri dari tasyahhud awwal

c. Bersedekap ketika berdiri

d. Mengarahkan pandangan kearah tempat sujud

e. Membaca do'a qunut

f. Bertasbih ketika ruku' dan sujud

g. Membaca do'a ketika duduk di antara dua sujud h. Mengucap salam kedua
Materi rukun shalat pada buku fiqh kurikulum Kementerian Agama RI ini menjelaskan sebagian saja dari sunnah-sunnah shalat seperti Mengangkat kedua tangan ketika ruku', berdiri dari ruku', dan berdiri dari tasyahhud awwal dll. Akan tetapi tidak disertai dengan dalil hadits sebagai dasar.

Sesuatu yang membatalkan shalat tentunya menjadi suatu yang menentukan apakah shalatnya sah atau tidak sah. Dengan demikian, tentunya sebagai seorang muslim harus mengetahui apa saja hal-hal yang membatalkan shalat.

Hal-hal yang membatalkan shalat di dalam buku fiqh kurikulum Kementerian Agama RI ada 7 macam, yaitu:

a. Meninggalkan salah satu rukun shalat atau memutuskan rukun sebelum sempurna dilakukan

b. Tidak memenuhi salah satu dari syarat seperti berhadas, terbuka aurat 
c. Berbicara dengan sengaja

d. Makan dan minum

e. Menambah gerakan shalat

f. Tertawa

g. Mendahului imam sebanyak 2 rukun

Materi hal-hal yang membatalkan shalat pada buku fiqh kurikulum Kementerian Agama RI ini ada 7 macam dan hanya menjelaskan secara global dan tidak disertai hadits sebagai dasar penguat pemahaman peserta didik.

\section{KESIMPULAN}

Materi shalat pada kitab Mabadiul Fiqhiyyah Juz II membahas tentang: syarat wajib shalat, syarat sah shalat, shalat fardhu dan waktunya, shalat sunnah yang mengikuti shalat fardhu, waktu-waktu yang diharamkan shalat, rukun shalat, sunnah-sunnah di dalam shalat, dan hal-hal yang membatalkan shalat. Sedangkan materi fiqh kurikulum Kementerian Agama RI. membahas tentang: syarat wajib shalat, syarat sah shalat, rukun shalat, sunnah-sunnah di dalam shalat, dan hal-hal yang membatalkan shalat.

\section{DAFTAR PUSTAKA}

Abday Rathomy, Moh. Tt. Pemulaan Fiqih. Surabaya: TB. Imam.

Ad-Dimyathi, Ahmad. Tt. adDimyathi 'Ala Syarhi Waroqoti. Jakarta: Al-Haromain Jaya.

Al Albani, Muhammad Nashiruddin. 2007. Shahih Sunan at-Tirmidzi

1. Jakarta: Pustaka Azzam

An-Nawawi, Imam. 2010. Syarah

Shahih Muslim. Jakarta:

Pustaka Azzam

Hasbiyallah. 2014. Figh dan Ushul Fiqh. Bandung: PT. Remaja Rosdakarya.

Kemenag RI. 2012. Al-Qur'an Terjemah. Jakarta: PT. Sinergi

Pustaka Indonesia

Nursyamsudin. 2012. Fiqih.

Jakarta: Direktorat Jendral Pendidikan Islam Kemenag RI. 